\title{
Translating research findings into educational policy and practice: the virtues and vices of a metaphor
}

\section{Martyn Hammersley}

A variety of metaphors have been used in seeking to conceptualise the relationship between social and educational research, on the one hand, and policymaking and practice, on the other. One influential analogy is the idea that research findings can and should be translatable into policy, and thereby into practice. This article will provide a conceptual analysis of the source meaning of "translation", and what is involved in this metaphorical use of it. It will be argued that many of the issues that arise in relation to translating text from one language into another have parallels in the task of communicating research findings to policymakers or practitioners. However, the idea that research findings can then be "translated" into policy and practice is much more problematic.

The metaphor of "translation" has been used in a variety of ways in the context of social and educational research. Of course, some research of this kind involves translation in a literal sense: the data or other source materials are in one language, or one language variant, and the research report is to be in another (Temple, 1997; Temple and Young, 2004; Tarozzi, 2013). More broadly, though, research that crosses cultural boundaries (and some writers argue that most research is of this kind) involves "cultural translation»: one culture has to be understood in terms of another (Turner, 1980). Equally, the production of transcriptions from audio- or video-recordings has sometimes been thought of as involving translation from one medium into another (from aural and/or visual into written form) (see Ross, 2010; Hammersley, 2010). There is also a sense in which researchers translate what informants say in interviews into evidence, and then translate this evidence into research findings. ${ }^{1}$ Beyond this, the production of synthetic reviews of multiple studies has been conceptualized by some as a process in which the terms of one study are translated into those of others (Noblit and Hare, 1988; Hammersley, 2013, ch11). However, the use of the translation metaphor that I will be focusing on here is different again: it concerns the interface between research, on the one hand, and policymaking and practice, of various kinds, on the other. However, as will become clear, this requires careful conceptual analysis. 
This use of the notion of translation is to be found across many areas of inquiry but it has become institutionalized in the field of medicine, leading to the development there of what is referred to as "translational research": research concerned with facilitating the turning of research findings into practical guidelines or new forms of practice. Along these lines, «knowledge translation» was defined by the World Health Organisation $(2006,2)$ as «the synthesis, exchange and application of knowledge by relevant stakeholders to accelerate the benefits of global and local innovation in strengthening health systems and advancing people's health». And considerable resources have been invested in knowledge translation research in the United States, the UK, and other countries (see Ioannidis, 2004; Goldblatt and Lee, 2010). There have also been proposals to extend this type of research to other areas including the field of education, sometimes accompanied by recognition of the obstacles that would need to be overcome for this to be possible (Brabeck, 2008; Levin, 2013). And the idea that educational research findings can be translated into recommendations for policy and practice can be found much more widely. For example, Marzano and Pickering $(2007,507)$ describe the "express purpose» of their book Classroom Instruction that Works (Marzano et $\mathrm{al}, 2001$ ) as «to translate the research pertaining to a number of instructional practices [...] into practical suggestions for classroom teachers». The practical problems involved in such "translation» have also been investigated (see, for instance, Coburn, 2001).

Of course, "translation» is only one of several metaphors that have been used to conceptualise the relationship between educational research, on the one hand, and policymaking and practice, on the other. Others include: «application», «dissemination», "enlightenment», "knowledge transfer», «knowledge mobilization», and «impact». Problems have been identified with many of these (see Hammersley, 2002 and 2014). For example, «impact» - now one of the most commonly used - is a physical metaphor in which research is assumed to carry within it some momentum for action on the part of policymakers and practitioners, with impact occurring when this momentum is transferred. Thus, in the now substantial literature on evidence-based practice, it is frequently assumed that research can demonstrate what policies and practices "work», and which do not; and the impact of this research is defined as a shift within practice towards "what works», or at least away from what does not. But can research legitimately claim to produce practical instructions of this kind? And should good practice be taken to mean blindly following the dictates of research, in the way that the impact metaphor implies? There are good reasons for denying both these propositions (Montgomery, 2006; Hammersley, 2013 and 2014). ${ }^{2}$

Interestingly, Greenhalgh and Wieringa (2011) criticise the translation metaphor along very similar lines to these criticisms of the other metaphors. They argue that it constrains our understanding of the relationship between research and practice. More specifically, they question three assumptions that underpin the metaphor: that knowledge amounts to «objective, impersonal 
research findings», rather than also including tacit knowledge; that «knowledge and practice can be cleanly separated both empirically and analytically»; and that practice consists of «a series of rational decisions on which scientific research findings can be brought to bear» ( $\mathrm{p} 503$ ).

Greenhalgh and Wieringa's argument is valuable in pointing to the significance of tacit knowledge, and to the socio-political contexts in which "translation" takes place. However, I suggest that there is much to be gained by exploring the metaphor of translation a little further, rather than simply rejecting it. It can be argued that those who have used this metaphor have not taken it seriously enough: they have paid insufficient attention to what it implies. ${ }^{3}$ In effect, they have assimilated it to other metaphors like «application» and «impact». As Greenhalgh and Wieringa (2011) make clear, its advocates have tended to assume that what is involved is the summarizing, packaging, and transmission of scientific knowledge to practitioners, and the incorporation of this within their practice. Along these lines, there has been much discussion of the role of "push" and «pull» factors in bringing about the "translation» of research findings into practice, and of barriers to this process. In other words, it seems to be assumed that what is involved is analogous to a physical process of transmission. ${ }^{4}$

Yet, if we examine the translation metaphor carefully we get a rather different, and in my view more fruitful, conceptualization of what is involved in the relationship between research and practice. Above all, this metaphor highlights the fact that it is a communicational and sociocultural process. I will begin, then, by examining the translation metaphor and the ways in which it can be illuminating, before turning later to consider the dangers associated with it.

\section{The source of the metaphor: Linguistic translation}

In evaluating any metaphor we need to examine the source meaning - the literal usage - with some care, and to consider which aspects of it are retained in the metaphor, and which are not; in other words, what transformation does the original meaning undergo in the process in the process of constructing the metaphor, and what are the implications of this? I will begin, then, by examining linguistic translation, what Jakobson (1959) calls «translation proper», before looking at what is inherited from this in thinking of research findings as «translatable» into practice.

There is a considerable literature dealing with translation in its literal sense of expressing what has been said or written in one language, or language variant, in a different one (see Brower, 1959; Lefevre, 1992, and Venuti, 2004, 2008). And diverse views can be found about what this involves, and about how translations are best produced. Indeed, there have even been doubts about whether translation is ever possible, as well as disagreements about what are better and worse translations of particular texts. 
Some writers have thought of translation as involving the application of procedures for identifying synonymous meanings in different languages, this often with a view to improving "machine translation»: automation of the translation process through computer software. Various programs have been developed that translate between some languages at some level of accuracy. ${ }^{5}$ What is involved here is the idea of language as a calculus, so that communication involves the coding of material for transmission, this then being decoded for reception and understanding; with translation requiring the coding of the meanings in a different language, so that speakers of this language can subsequently decode them.

Interpreted in these terms there may not be much difference between using the translation metaphor and employing the other metaphors typically employed to understand the relationship between research and practice: in both cases a process of controlled transmission is assumed. However there is another, rather different, view about the nature of linguistic translation, carrying very different metaphorical implications. It is often insisted that translation necessarily relies upon tacit knowledge and judgment, and therefore is not reducible to procedures. This view can be seen as relying upon the idea of language as a medium (Hintikka \& Hintikka, 1986; Kusch, 1989). From this point of view, meaning is constituted in and through the use of particular linguistic resources in particular contexts, and there is no way of stepping outside of these, for example by relying upon abstract procedures: we must simply work within them. Here, communication itself becomes an uncertain and partial process. In other words, cultural translation is viewed as ubiquitous; with linguistic translation as simply a more difficult and uncertain form of communication, in which some mediation has to be found between the two languages (Eco, 2003). In these terms, Ricoeur (2006) presents translation as a model for the discipline of hermeneutics, while Steiner (1975) conceives all understanding as translation (see also Roth, 2013). Underlying this perspective is recognition that what must be translated is not simply the words that are used but the whole range of resources available in a language that are employed in the source text. Thus, while translating some texts may be relatively straightforward, for instance those involving simple descriptions or instructions, translating others will be viewed as close to impossible, notably much poetry. ${ }^{6}$

There is much to be said in favour of this second approach: it undoubtedly captures the character of linguistic translation better than the first. It implies that there are barriers to translation that stem from the very nature of human communication, that it is not a rule-governed but at most only a rule-guided activity. As a result, there are differences among languages that undercut any simple correspondence between a phrase in one and a similar phrase in others. These operate at the level of vocabulary - the ontological landscape is carved up somewhat differently by different languages, to one degree or another - but also at the level of grammar (Whorf 1956). Ricoeur $(2006,6)$ writes that: 
Not only are the semantic fields not superimposed on one another, but the syntaxes are not equivalent, the turns of phrase do not serve as a vehicle for the same cultural legacies; and what is to be said of the half-silent connotations, which alter the best-defined denotations of the original vocabulary, and which drift, as it were, between the signs, the sentences, the sequences whether short or long. It is to this heterogeneity that the foreign text owes its resistance to translation and, in this sense, its intermittent untranslatability.

Beyond this there is the task of conveying sound symbolism - since sometimes the aim of writing is also to capture prosodic and paralinguistic features of speech (Crystal, 2010, 177). This points to even more elusive ways in which languages differ:

That which translates worst from one language into another is the tempo of its style, which has its origin in the character of the race, or, expressed more physiologically, in the average tempo of its «metabolism». There are honestly meant translations which, as involuntary vulgarizations of the original, are almost falsifications simply because it was not possible to translate also its brave and happy tempo, which leaps over and puts behind it all that is perilous in things and words. The German is virtually incapable of presto in his language; thus, it may be fairly concluded, also of the most daring and delightful nuances of free, free-spirited thought. Just as the buffo and the satyr is strange to him, in body and in his conscience, so Aristophanes and Petronius are untranslatable for him. (Nietzsche, 1973, part 2, section 28)

While some, like Nietzsche, have suggested that the differences between languages make translation impossible, others have adopted a more pragmatic position, according to which, while exact or perfect translation is ruled out, various levels and types of inexact translation are possible and worthwhile, these being suitable for different purposes (Crystal, 2010, 354), or valuable for allowing different kinds of understanding (Ricoeur, 2006).

At the very least, what all this makes clear is that trying to produce a translation that remains true to the original yet at the same time is intelligible to the target audience is a challenging task that demands deep knowledge of the languages involved as well as thoughtful judgment. Idiomatic usage must be captured, and more generally the connotations associated with particular words or phrases in each language must be borne in mind. For this reason, «free» translations may be truer to the original than literal ones, insofar as this distinction can be maintained. 7

One way of formulating this distinction is to draw a contrast between translations that retain the foreign character of the original text and those that work to domesticate it in relation to the target language. Schleiermacher $(1813 / 2004,49)$ writes: «Either the translator leaves the author in peace as much as possible and moves the reader toward him; or he leaves the reader in peace as much as possible and moves the writer toward him». In the first case readers are challenged to 
work at understanding what is alien to them, whereas in the second the cultural differences are erased as far as possible, bringing the text within the parameters of reader culture.

It is worth adding that a key aspect of what is recognized here is that, to one degree or another, those using different languages live in different experiential worlds, so that some means must be found to negotiate the cultural differences involved. Take the example of translating a novel like Don Quixote from its original Spanish into modern-day English. Aside from the basic problems of language difference, it will also be necessary to take account of the different cultural worlds that the author and the new audience inhabit. And, of course, some of these problems would also arise in preparing a modern edition of this book in Spanish. ${ }^{8}$ What must be acknowledged here are discrepancies in preoccupations and experience, attitudes and values. Not only will the translation need to accommodate these but an introduction to the text may be necessary to help present-day readers understand the «point» or purpose of the book, how the narratives it contains relate to the world that Cervantes and his first audiences inhabited, and how these differ from the world today (see, for example, Russell, 1985). It may also be necessary, as Benjamin $(1973,8)$ amongst others has suggested, to modify the very language into which the translation is being made so that it can accommodate relevant features of the source language. In other words, the resources of the destination language may need to be developed in ways that reflect the character of what is being translated.

At the same time, while it is recognized that much can be lost in translation, there can be gains as well: the re-contextualisation of ideas can be illuminating and fruitful (see Eco, 2003, 6 and passim). Thus, Calvino (1995, cited in Tarozzi, 2013) has argued that translating a text into a different language is the best way of coming to understand it. For this and other reasons the cultural negotiation involved in translation is often regarded as of great value (Ricoeur, 2006).

As I will try to show, these various aspects of linguistic translation can tell us quite a lot about the complexities of the relationship between research findings and policy or practice.

\section{Applying the metaphor of translation}

In thinking about translation as a metaphor for the relationship between research and policymaking/practice, there are two components that need to be examined separately. First, there is the communication of research findings to lay audiences; secondly, there is the process of turning research findings into practical action. I will examine these in turn. 


\section{Communicating research findings}

It is easy to recognize correspondences between the translation of textual material from one language to another and the communication of research findings to policymakers and practitioners. At the most basic level, there may be discrepancies between some of the language used by researchers and what is intelligible to other audiences. Complaints have often been made about scientific jargon, and more broadly about the overly complex language that social scientists use (see, for example, Toynbee, 1999). Problems can arise at the level of grammar as well as vocabulary - this may need to be simplified, sentences shortened, etc. - but the structure and length of reports will also often have to be modified. For instance, where academic articles or books typically build up to presenting conclusions at the end, reports for lay audiences will often need to present the «news» they are conveying upfront, with subsequent paragraphs providing more detail and qualification. A common form here is, of course, the «executive summary».

However, the parallels go beyond this basic level. Here, too, what is involved is an attempt to bridge different experiential worlds or cultures. Educational policymakers and practitioners will not usually share the same typical experiences, ways of conceptualizing the world, preoccupations and priorities, attitudes and prejudices, as researchers. There will be differences even at the level of what is taken as known, and what is treated as fixed and unchangeable (Taylor, 1973; Hammersley 2002, ch3, 2011, ch5). These differences reflect, in large part, the divergent purposes of the different occupations, and the varying conditions in which their members work. Moreover, at issue here is not just intelligibility but also the apparent relevance or irrelevance of the research findings, and their face validity in terms of the audience's background assumptions.

Indeed, in this respect, communication of research findings to lay audiences involves many of the considerations involved in translating a classic novel of the past into a different language and for a present-day audience. Here some attention must be paid not only to how people will understand particular words, phrases, and sentences but also to what they will and will not know about the phenomena referred to, and what they will and will not find interesting and of use. Without adopting an extreme version of reader reception theory, according to which texts are only given meaning in the process of being read (Fish, 1980; Holub, 1984), we should nevertheless recognize that a two-way process is involved here. Lay audiences necessarily interpret communications reporting research findings in terms of their own background knowledge, purposes, and interests. In approaching the text, in seeking to identify its message, and in drawing significant conclusions from it, they will construct meanings that are understandable, persuasive, and valuable for themselves. Given this, the relationship between the message intended by researchers and how that text will be «received» and used will be highly mediated, to say the least. Sometimes the conclusions drawn will be sharply at odds with what was expected, or desired, by researchers. 
As in the case of linguistic translation, there are two main ways in which a research report for lay audiences can be defective: its representation of the scientific knowledge it purports to communicate may be inaccurate, or it could fail to be intelligible, believable, or of interest to the target audience. There has been considerable discussion of the first of these problems in the context of the popularization of natural scientific knowledge (see Cornelis, 1996; Zevin, 2008), the implication sometimes being that some «betrayal» of the original cannot be avoided. Issues that arise here concern how research findings can be communicated in simpler language without losing important complexities; and what details and qualifications can be left out without the message being misleading.

There is also a parallel here with the tension between translations that are more foreign and those that are "domesticated». To recapitulate, the argument for foreignness values a learning process in which something «other» is allowed to modify the target language, or at least to change the understanding and experience of readers. At the same time, the danger of foreignness is that the translation will be unintelligible, misunderstood, and/or unappealing - and therefore ignored or rejected. By contrast, domesticated translations may manage broadly to convey what was written in the foreign language in ways that are easily intelligible and appealing, but at the cost of losing much of the original sense. Applying this to the case of communicating research findings, there are difficult choices involved: a report for lay audiences that stays close to the language and character of academic discourse may retain what is distinctive and new in ways that will be lost in the case of a more popularizing discursive mode. However, this may be at the cost of its intelligibility and appeal.

Moreover, there can be important tensions between the actual preferences of lay audiences and what might be thought necessary if they are properly to understand research findings. For example, it is sometimes argued that policymakers and practitioners will not be interested in methodology - in information about how the findings were produced. This may be true, but one could reasonably suggest that they ought to be interested in this, at least to some degree. Otherwise, the implication would be that they should simply accept research findings at face value or, alternatively, that they ought to interpret and evaluate them entirely in terms of whether or not these conform to what they already believe. Neither alternative seems desirable.

Yet, if the need to provide methodological information is accepted, this complicates considerably the task of communicating research findings, since means must be found of persuading readers to attend to this information, along with some way of facilitating their understanding of it: at the very least, the preferences or at least the tolerances of the audience will need to be reshaped. Furthermore, as Greenhalgh and Wieringa (2011) point out, this kind of translation takes place in contexts where there are significant power differences that may represent major barriers. In relation to policymakers, researchers will often 
be in a relatively weak position to attempt any reform of their preconceptions. And, even when researchers are in a more powerful position, for example in communicating their findings to some sorts of occupational practitioner, there may still be resistance. Audience members will, more than likely, already have their own views about the matters concerned, in which they have some investment. Indeed, as in some cases of linguistic translation, "translation» may be viewed as an attempt at conquest (Nietzsche, 1974, 136-8).

A related issue concerns who should carry out the process of translation. In linguistic translation it is often argued that it is best if translators work into their native language. Yet, generally speaking, in the case of «translating» research findings for lay audiences it is researchers themselves who are the translators, and they are often translating into a «language» that they know only poorly. But if the task of "translation» is switched to the representatives of policymakers or practitioners, will this not increase the danger that much will be lost or distorted in the process?

In summary, then, like linguistic translation, the communication of research findings is a complex, socio-cultural process; and it is not just a matter of how researchers present their findings (in what form, by what means, and in what context) but also of what degree and kind of attention policymakers and practitioners will give it, and of how far they seek to understand what is being communicated in its own terms. As with linguistic translation, while we might wish to insist that translation is possible, we must recognize the considerable difficulties and dangers that may arise.

\section{Translating research into practice}

As I noted earlier, the communication of research findings to policymakers and practitioners is only part of what is usually involved in applying the metaphor of translation to the relationship between research and policymaking or practice. Often, it is also required that research findings then be translated into policies or practices. This, I suggest, is where the metaphor breaks down.

First of all we can note that this usage of the metaphor assumes that research and practice are equivalent to two languages: in their character and operation, and in their relationship to one another. But this is not true: it is reasonable to treat researchers' communications to lay audiences as analogous to translation between two languages, but as I have noted research and policymaking/practice are distinct activities with very different goals, operating in very different contexts. They do not resemble languages at all closely. Here there are few parallels with the source meaning.

A central problem is that the idea of «translating research findings into practice» assumes that those findings take the form of practical instructions for action, or that such instructions can be derived from them in a relatively straightforward, unmediated fashion. Of course, there are those who argue that research can legitimately move from establishing descriptive and explanatory 
facts to drawing and presenting normative conclusions about what is good or bad, right or wrong, and about what should, and should not, be done (see, for example, Sayer, 2011). If this were true, the translation of research findings into action might be viable, but it is not (Hammersley, 2014, chs4 and 5).

The most straightforward case is where research reports include recommendations for action. But what is the relationship between these recommendations and the factual conclusions generated by the research? The answer is that it is necessarily a rather weak one. Drawing value conclusions from factual research evidence necessarily involves relying upon a range of value assumptions that the research itself cannot validate. Moreover, any change in those assumptions will generally produce significantly different evaluations or recommendations. In other words, value conclusions are radically underdetermined by factual evidence, whether these conclusions are drawn by researchers or by lay people. Equally important, practical decisions rely upon processes of phronesis, rather than amounting to the implemention of a set of rules; and this is true even where these decisions are legitimated through appeal to research evidence (Dunne, 1997).

Given this, rather than policymakers and practitioners seeking to "translate» research findings into action, we must see them as interpreting and assessing relevant evidence, including that from research, in such a way as to allow them to deliberate effectively in setting goals and determining appropriate means, or in diagnosing problems and seeking effective solutions. Research evidence can play a variety of roles in this process, from filling in missing information to facilitating a reformulation of the goal aimed at or the problem identified (Hammersley, 2002, Conclusion). However, it cannot provide instructions that are then implemented, in the way that the translation metaphor implies.

It is also important to recognise that what is involved here may be a three-way relationship, not just a two-way one. This is true where research findings are first to be translated into policies, with these policies then being "translated» into practice. Similar problems of mediation arise in the second leg of this process as in the first. Much research on the relationship between policy and practice makes clear that policies have complex trajectories, being interpreted and acted on in a variety of ways in different contexts and at different times, this being shaped by the background assumptions, interests and circumstances of various agents engaged in «applying» them (Ball, 1993). In other words, those at different levels of, or in different parts of, an education system may well interpret the policy, and any research findings on which it is based, in different ways and also be motivated to act on it differently because of local contingencies and constraints.

We can think of the relationships among research, educational policymaking, and educational practice as having something of the character of an eternal triangle, in which there are inevitable tensions whose management tends to generate further conflict, without any resolution. Each of the three enterprises pulls in somewhat different directions, while yet having to maintain a 
relationship with the others. Of course, the parties certainly do not have equal power, but even the most powerful is not able entirely to control the others. Moreover, not only does the character of the three activities change somewhat over time, partly in adjusting to the pressures of their relationships, but the triangle operates in a socio-historical context that also shifts in significant ways, introducing exogenous pressures and opportunities into the system. Also, as in other kinds of eternal triangle, we find that myths are generated about the relationships involved, along the lines that if only one or more of the parties were to behave "properly» relationships would be smooth. One of these myths is precisely the idea that if social and educational research were carried out effectively its findings would be "actionable», in other words could be "translated" into policies and thereby into practice. For the reasons I have explained, this is a fallacy.

In summary, then, it is quite misleading to assume that research findings can be «translated» into action, and any attempt to do this is likely to distort good practice in significant ways, as well as misrepresenting the research findings supposedly translated. In this respect, the metaphor of translation is fundamentally unsatisfactory, in much the same way as are most of the other metaphors that have been used to conceptualise the relationship between research and policymaking/practice. It obscures what is involved, and may serve ideological functions.

\section{Conclusion}

In this article I have argued that, in some important respects, «translation» can be a fruitful metaphor for thinking about the relationship between research, on the one hand, and policymaking and practice, on the other. For this to be possible we need to recognize that linguistic translation is not a procedural process that can be programmed but is instead socio-cultural and interpretative in character. This provides important insights into the communication of research findings to lay audiences. In particular, it points to the fact that this involves bridging different experiential and cognitive "worlds", and the divergent attitudes and sensibilities that predominate there. At the same time, the metaphor of translation becomes very problematic when the relationship between research and practice is formulated as the translation of research findings into effective interventions and thereby into desirable outcomes. Here, little or nothing of the model of linguistic translation applies, even when we view it as an interpretive process. Indeed, use of the metaphor becomes systematically misleading. In particular, what is erased is recognition that research and the various forms of policymaking and practice it can inform are very different activities, with functions that are in permanent tension with one another. 


\section{Notes}

1 See Turner and Factor, 1994, 18-23, for an account of Max Weber's argument that social scientific analysis involves translating the social world of everyday action into social science terms, in a way that parallels legal reformulations of everyday moral understandings of action. See also White, 1990, on «justice as translation». There is also the interesting case of the "translation" of scientific evidence into legal terms that happens when expert witnesses give evidence in court, see Dwyer, 2009.

2 On the negative effects for social science that can result from pressure on it to have «impact», see Holmwood (2011).

3 Articles that appear to promise deeper attention to the metaphor often fail to provide this, in my view. See for example Hedges (2007) and Graham and Tetroe (2007).

4 Ironically, this is true even of purportedly radical versions of «translational research", including those in the field of education. Thus, Smith and Helfenbein (2009, 91, emphasis added) write that: "Translating Research into Practice (TRIP) is a research framework gaining a foothold in professional schools such as Medicine and Nursing and within the Liberal Arts in areas such as Communication Studies. TRIP values the timely application of new knowledge discovered through the research process. Its goals include the desire to move innovation into the marketplace at a faster pace, to facilitate evidence-based practice in professions such as nursing, and, ultimately, to bring to bear university resources and research to pressing issues facing our citizens and communities $[\ldots]$ ». Here, while a «new» approach is recommended involving a collaborative and interactive design, the assumptions made about the relationship between research findings and practice still seem to involve what might be called a transmission model.

5 For amusing examples of the failings of such translation, see Eco $(2003, \operatorname{ch} 1)$ and Tarozzi (2013).

6 Or the work of a writer like Derrida: see the reference in Peeters $(2013,371)$ to the problems that Derrida faced when switching to English in order to teach at the University of California. Interestingly, contrary to this line of argument, Benjamin $(1973,81)$ suggests that the more a source text is concerned with conveying information the less open to translation it is - on the grounds that it is pure language, the Logos, that speaks through a translation. The premise of his argument seems to be one version of the logocentrism that Derrida challenges. On Derrida and translation, see Graham (1985) and Venuti (2003).

7 Eco $(2003,5)$ illustrates how free translation is necessary in translating idiomatic expressions. On the distinction between literal and free translation, see Hatim and Mason (1990, 5-6). For one challenge to it, see Benjamin (1989, ch1 and passim).

8 In much the same way, Steiner $(1975,1-8)$ elaborates on the problems involved in «translating» the work of Shakespeare for modern English audiences.

\section{References}

Ball, S. (1993). What is policy? Texts, trajectories and toolboxes. Discourse: Studies in the Cultural Politics of Education, 13, (2) pp. 10-17.

Benjamin, A. (1989). Translation and the Nature of Philosophy. London: Routledge.

Benjamin, W. (1973). The task of the translator. In W. Benjamin, Illuminations. London: Fontana.

Brabeck, M. (2008). Why we need "translational” research: putting clinical findings to work in classrooms. Education Week, 27 (38), pp. 28, 36. Retrieved February 22, 2014, from http://www.edweek.org/ew/articles/2008/05/21/38brabeck.h27.html?tkn=WZPFlVcs\%2Fwi10uRbIjjhYf46Kky7hkoon\%2FLC\&intc=es

Brower, R. (Ed.) (1959). On Translation. New York: Oxford University Press. 
Calvino, I. (1995). Tradurre è il vero modo di leggere un testo. In M. Barenghi (Ed.), Saggi 1945-85, Vol. II, pp.1825-1831). Milan: Mondadori.

Coburn, C. (2001). Collective Sensemaking about Reading: How Teachers Mediate Reading Policy in Their Professional Communities. Educational Evaluation and Policy Analysis, 23 (2), pp. 145-170.

Cornelis, G. (1996). Editorial: Is popularization possible? Communication and Cognition, 29 (2), pp. 149-52. (Whole issue of this journal deals with the popularization of science.)

Crystal, D. (2010). The Cambridge Encyclopedia of Language (3rd edition). Cambridge: Cambridge University Press.

Dunne, J. (1997). Back to the Rough Ground: Phronesis and Techne in Modern Philosophy and in Aristotle. Notre Dame, IN: University of Notre Dame Press.

Dwyer, D. (2009). The Judicial Assessment of Expert Evidence. Cambridge: Cambridge University Press.

Eco, U. (2003). Mouse or Rat? Translation as negotiation. London: Weidenfeld and Nicolson.

Fish, S. (1980). Is There a Text in this Class? The authority of interpretive communities. Cambridge, MS: Harvard University Press.

Goldblatt, E. \& Lee, W-H (2010). From bench to bedside: the growing use of translational research in cancer medicine. American Journal of Translational Research, 2 (1), pp. 1-18.

Graham, I. \& Tetroe, J. (2007). Some theoretical underpinnings of knowledge translation. Academic Emergency Medicine, 14 (11), pp. 936-41.

Graham, J. (Ed.) (1985). Difference in Translation. Ithaca, NY: Cornell University Press.

Greenhalgh, T. \& Wieringa, S. (2011). Is it time to drop the "knowledge translation" metaphor? A critical literature review. Journal of the Royal Society of Medicine, 104 (12), pp. 501-9.

Hammersley, M. (2002). Educational Research, Policymaking and Practice. London: Paul Chapman/Sage.

Hammersley, M. (2010). Reproducing or constructing? Some questions about transcription in social research. Qualitative Research, 10 (5), pp. 1-17.

Hammersley, M. (2011). Methodology, Who Needs it? London: Sage.

Hammersley, M. (2013) The Myth of Research-based Policymaking and Practice. London: Sage.

Hammersley, M. (2014). The Limits of Social Science: Causal explanation and value relevance. London: Sage.

Hatim, B. \& Mason, I. (1990). Discourse and the Translator. London: Longman.

Hedges, J. (2007). The knowledge translation paradigm: historical, philosophical and practice perspectives. Academic Emergency Medicine, 14 (11), pp. 924-7.

Hintikka, M. \& Hintikka, J. (1986). Investigating Wittgenstein. Oxford: Blackwell.

Holmwood, J. (2011). Viewpoint - The impact of "impact" on UK social science. Methodological Innovations Online, 6 (1), pp. 13-17.

Holub, R. (1984). Reception Theory: a critical introduction. London: Taylor and Francis.

Ioannidis, J. (2004). Materializing research promises: opportunities, priorities and conflicts in translational medicine. Journal of Translational Medicine, 2 (5). Retrieved April 17, 2014, from http://www.translational-medicine.com/content/2/1/5.

Jakobson, R. (1959). On linguistic aspects of translation. In Brower (Ed.). Reprinted in Venuti (Ed.).

Kusch, M. (1989). Language as Calculus Versus Language as Universal Medium. Dordrecht: Kluwer.

Lefevre, A. (Ed.) (1991). Translation/History/Culture. London: Routledge.

Levin, B. (2013). To know is not enough: research knowledge and its use. Review of Education, 1 (1), pp. 2-31.

Marzano, R., Pickering, D. \& Pollock, J. (2001). Classroom Instruction That Works: ResearchBased Strategies for Increasing Student Achievement. Alexandria, Va.: Association for Supervision and Curriculum Development. 
Marzano, R. \& Pickering, D. (2007). Errors and allegations about research on homework. Phi Delta Kappan, 88 (7), pp. 507-513.

Montgomery, K. (2006). How Doctors Think: Clinical judgment and the practice of medicine. New York: Oxford University Press.

Nietzsche, F. (1973). Beyond Good and Evil. Harmondsworth: Penguin. (First published in German in 1886.)

Nietzsche, F. (1974). The Gay Science. New York: Vintage. (First published in German in 1887.)

Noblit, G.W. and Hare, R.D. (1988) Meta-ethnography: Synthesizing Qualitative Studies, Newbury Park CA, Sage.

Peeters, B. (2013) Derrida, Cambridge, Polity.

Ricoeur, P. (2006). On Translation. London: Routledge.

Ross, J. (2010). Was that Infinity or Affinity? Applying Insights from Translation Studies to Qualitative Research Transcription. Forum: Qualitative Social Research, Vol. 11/2. Retrieved from http://www.qualitative research.net/index.php/fqs/article/view/1357/2942.

Roth, W. - M. (2013). Translation in Qualitative Social Research: The Possible Impossible, [49 paragraphs]. Forum Qualitative Sozialforschung/Forum: Qualitative Social Research, 14 (2), Art. 13. Retrieved from http://nbn-resolving.de/urn:nbn:de:0114-fqs1302132.

Russell, P. (1985). Cervantes. Oxford: Oxford University Press.

Sayer, A. (2011). Why Things Matter to People: Social science, values and ethical life. Cambridge: Cambridge University Press.

Schleiermacher, F. (2004). On the different methods of translating. In Venuti (2004). (First published in German in 1813.)

Smith, J. S. \& Helfenbein, R. (2009). Translational research in education: Collaboration \& commitment in urban contexts. In W. S. Gershon (Ed.), The collaborative turn: Working together in qualitative research (pp. 89-104). Rotterdam: Sense.

Steiner, G. (1975). After Babel. London: Oxford University Press.

Tarozzi, M. (2013). Translating and Doing Grounded Theory Methodology: Intercultural Mediation as an Analytic Resource, [47 paragraphs]. Forum Qualitative Sozialforschung/ Forum:

Qualitative Social Research, 14 (2), Art. 6. Retrieved from http://nbn-resolving.de/urn:nbn:de:0114-fqs130263.

Taylor, W. (1973). Knowledge and research. In W. Taylor (Ed.), Research Perspectives in Education. London: Routledge and Kegan Paul.

Temple, B. (1997). Watch your tongue: issues in translation and cross-cultural research. Sociology, 31 (3), pp. 607-18.

Temple, B. \& Young, A. (2004). Qualitative research and translation dilemmas. Qualitative Research, 4 (2), pp. 162-78.

Toynbee, P. (1999). Interview (with Liam Murphy). Network, Newsletter of the British Sociological Association, 72, 20-3.

Turner, S. P. (1980). Sociological Explanation as Translation. Cambridge: Cambridge University Press.

Turner, S. P. \& Factor, R. A. (1994). Max Weber: The lawyer as social thinker. London: Routledge.

Venuti, L. (2003). Translating Derrida on Translation: Relevance and Disciplinary Resistance. Yale Journal of Criticism, 16 (2), pp. 237-62.

Venuti, L. (Ed.) (2004). The Translation Studies Reader, (2nd edition) London: Routledge.

Venuti, L. (2008). The Translator's Invisibility: A history of translation, (2nd edition). London: Routledge.

White, J. (1990). Justice as Translation. Chicago, IL: University of Chicago Press.

Whorf, B. L. (1956). Language, Thought and Reality. New York: Wiley.

World Health Organization (2006). Bridging the "Know-Do» Gap, Geneva, World Health 
Organization. Retrieved April 18, 2013, from http://www.who.int/kms/WHO_EIP_ KMS_2006_2.pdf?ua=1 Retrieved April 92014

Zevin, J. (2008). The perils of popularising science. Intelligent Life, The Economist, January 23rd. Retrieved February April 17, 2013, from http://moreintelligentlife.co.uk/story/ the-perils-of-popularising-science

Key words: Knowledge translation, research and policymaking, knowledge mobilisation.

\section{Übersetzung von Forschungsergebnissen in bildungspolitische Programme und die Praxis: Tugend und Laster einer Metapher}

\section{Zusammenfassung}

Eine Reihe von Metaphern wurden mit dem Anliegen genutzt, die Verbindung zwischen sozial- und erziehungswissenschaftlicher Forschung auf der einen Seite sowie bildungspolitischen Programmen und daraus resultierende Praxis auf der anderen Seite zu konzeptualisieren. Eine viel gebrauchte Metapher in diesem Zusammenhang ist die der Übersetzbarkeit. Sie umfasst die Idee, dass Forschungsergebnisse in bildungspolitische Programme und damit die Praxis übersetzbar sind und sein sollen. Der vorliegende Artikel legt eine konzeptionelle Analyse der verschiedenen Bedeutungen von «Übersetzung» auf verschiedenen Ebenen vor. Es wird dargelegt, dass es viele Parallelen gibt zwischen der Übersetzung eines Textes in eine andere Sprache und der Aufgabe, Bildungspolitikerinnen und -politikern sowie Personen in der Praxis Forschungsergebnisse zu kommunizieren. Es zeigt sich jedoch, dass diese Idee von Übersetzung nicht unproblematisch ist.

Schlagworte: Übersetzen von Wissen, Forschung und Bildungspolitik, Wissenstransfer.

\section{Traduire les résultats de la recherche en politiques et pratiques éducatives: vertus et biais des métaphores}

\section{Résumé}

De multiples métaphores sont utilisées afin de conceptualiser les relations entre la recherche sociale et éducationnelle d'une part, les politiques et pratiques scolaires d'autre part. L'idée selon laquelle les résultats de recherches peuvent et doivent être traduisibles en politiques, et, par là, dans les pratiques, constitue une métaphore influente. Cet article propose une analyse conceptuelle du sens de «traduction» et de ce qu'implique et comporte son usage métaphorique. Nous montrerons que nombre de problématiques liées à la traduction linguistique de 
textes d'une langue dans une autre ont leur équivalent lorsqu'il s'agit de communiquer des résultats de recherche aux politiciens et praticiens en éducation. L'idée que les résultats de recherche peuvent être traduits en politiques et pratiques est cependant encore nettement plus problématique.

Mots-clés: Traduction, vulgarisation des connaissances, recherche en éducation, politiques et pratiques éducatives, transfert de connaissances, mobilisation de connaissances.

\section{La traduzione dei risultati di ricerca in politiche educative e nella pratica: i vizi e le virtù di una metafora}

\section{Riassunto}

Molte diverse metafore sono state usate cercando di concettualizzare la relazione tra ricerca sociale ed educativa da un lato, e le politiche e le pratiche dall'altro. Un'analogia influente è l'idea che i risultati di ricerca possano e debbano essere traducibili in politiche e quindi in pratiche. Questo articolo offre un'analisi concettuale del significato originale di "traduzione» e di che cosa sia implicato nel suo uso metaforico. Si argomenterà che molte delle questioni che emergono in relazione alla traduzione di un testo da una lingua all'altra hanno dei parallelismi con il compito di comunicare i risultati della ricerca ai decisori e ai professionisti. Ciononostante, l'idea che i risultati della ricerca possano essere "tradotti" in poliche e pratiche resta molto più problematica.

Parole chiave: traduzione di conoscenze, ricerca e politiche educative, mobilitazione delle conoscenze. 